\title{
Editorial
}

\section{President Obama: Protect everyone's health while paying for patient care}

Journal of Public Health Policy (2009) 30, I-2. doi:I0.I057/jphp.2009.I

Along with so many others in the United States, we celebrate a new opportunity, with the election of President Barak Obama, to reform our health system. But, as we did in 1994 (when the Clinton era health reform debates raged, and long before we were the Co-Editors of this journal), we urge everyone involved to consider how to make improving health among the highest priorities in medical care reform. It may sound obvious, but history proves quite the opposite: protecting and improving the health of the public rarely features in debates about 'health reform', nor in legislative proposals. Thus, we provide a link with the full text of our I 994 contribution to JPHP on this crucial set of issues (http://www.palgrave-journals.com/jphp/ Formula_for_Failure.pdf).

The article begins: 'Because renewed energy for health care reform springs from perceptions of risk that center more on economic than on physical vulnerabilities, so too do the remedies. Detailed attention from dozens of consultants to cost containment and to financing universal access to medical services has obscured what should be a decisive distinction between proposals. Do they attend to improving health and reducing disease or only to paying for diagnosis and treatment for those already ill? ... If we accept the pervasive perception that universal access to medical services will address every important health need, we will miss a magnificent chance to prevent disease and to hold off unnecessary medical care expenditures.' (We included injuries, mental health, and every other condition that may compromise health among the 'physical vulnerabilities.')

As we warned then, we reiterate emphatically here: '... if we do not get this right now, the door of political opportunity may not open for a second chance for many years... Impending health care reform could take advantage of the extensive medical services system, at little additional cost, to accomplish many previously 
unattainable health goals for the nation, but nothing about the planning process or debate so far makes that outcome seem likely. Repeated references during the debate on health care reform to "access to prevention services" belie a failure to understand the difference between insuring personal health services and assuring public health gains. The distinction is a strategic one. Public health is grounded in the Constitutional authority to protect the health and safety of the entire population. In contrast, medical care is oriented to the needs of the individual. Medical services can be preventive, curative, or palliative. Good medical care can have a favorable effect on public health even if the services were not offered as features of a population-based strategy. But our nation will never achieve optimal health from our enormous investments in the medical care system without explicitly integrating public health guidance and accountability into the reform of medical care management and finance.'

We are painfully aware that the United States spends more per capita on health services than any other country, yet does not have health outcomes that reflect well on this impressive investment. We welcome comments and letters on this crucial set of issues from colleagues within the United States - and from around the world.

The Co-Editors 